oped by these early geniuses, who should still be honored. As a manual the work should be in the hands of every student of superficial geology, and must form one of his most valuable works of reference. In a great manner the conclusion of the author will be most acceptable. On other points, differences of opinion will prevail here as in the works of all other philosophic writers. The title of the book is its sensational feature, and might awaken more opposition than its general judicial character would give rise to.

\section{J. W. Spencer.}

The Etiology of Osseous Deformities of the Head, Face, Jaws and Teeth. By Eugene S. Talbot, M. D., D. D. S. Third Edition. Revised and enlarged, with 461 illustrations. Chicago, The W. T. Keener Company. Pp. 487.

Dr. Talbot's work is a most ambitious one, and this is perhaps its chief fault. It contains an enormous amount of facts and figures gathered from every source and touching upon every question from anthropology and crime to the useful art of taking care of the teeth. If the doctor could have condensed his book and given it a little more proportion and coherence it would appeal much more to the general and scientific reader. As it is, we find in it much original observation and a multitude of anatomical and anthropological facts which are interesting and should prove useful.

An excellent example of the author's work is shown in his chapter on developmental resources. Here he starts with the simple problem of the palatal arch in idiots and ends in a discussion of the general problem of osseous deformities as related to the different forms of degeneration. Dr. Talbot is manifestly a follower of Morel and Lombroso and adds many facts in support of the view that characteristic stigmata accompany the degenerative state. We must add again, however, that he fails to take what we would consider a properly conservative view of the question, and, while he gives many valuable data regarding criminals, he does not, we think, consider sufficiently the anatomy of the normal man of the low social stratum from which most of his criminals come. Lombroso has himself abandoned anthropometrical measurements as affording much help in establishing a criminal type.

We must add, in conclusion, and in justice to Dr. Talbot, that we know of no American who has made so many personal observations and measurements on the defective classes, and he is entitled to great credit for his work. Charles L. Dana.

\section{DOUBLE REFRACTION IN WOOD.}

Doppelbrechung electrischer Strahlen. $\mathbf{K}$. MAck. Wied. Ann. 54, 1895, p. 342.

Bemerkung über die Abhandlung von Herrn Mack. W. von Bezold. Ibid. 54, 1895, p. 752 .

Doppelbrechung electrischer Strahlen. A. RIGHI. Ibid. 55, 1895, p. 389.

Mr. Mack's article describes an interesting series of experiments to demonstrate that plates of wood exhibit a double refraction of electric waves. The sender and receiver were so arranged, with spark gap and reflectors, that the waves were $50-60$ $\mathrm{cm}$. in length. The test for double refraction in light is the lightening up of the field when the substance is introduced between crossed Nicols ; similarly, Mr. Mack tested for double refraction of electric waves by introducing plates of wood between crossed sender and receiver. The first plates were of fir-tree $0,5-1,0$ sq. M. area and $2,3 \mathrm{~cm}$. thick, and gave negative results. An octagonal plate of fir about 60 $\mathrm{cm}$. in diameter and $20 \mathrm{~cm}$. thick was afterward used, and showed a decided double refraction when its fibres were $45^{\circ}$ to the sender and receiver, and also between parallel sender and receiver showed 
greater absorption when its fibres were parallel than when they were perpendicular to the plane of the vibrations. That is, the wood is double refracting and transmits best when the plane of vibration is perpendicular to the direction of the fibres and absorbs most when they are parallel. In fact, to this absorption the author ascribes the reappearance of the sparks with the crossed sender and receiver, since the plates of wood were not thick enough to give a retardation of one ray behind the other equivalent to a half wave-length; in fact, the plates were only from $\frac{1}{6}$ to $\frac{1}{2}$ a wavelength thick. The phenomenon was observed with plates up to $35 \mathrm{~cm}$. thick and of fir, oak and beech. Plates cut perpendicular to the fibre showed no double refraction as was anticipated. The author refers to the experiments of Starkl showing that the thermal conductivity of wood is different, parallel with and perpendicular to the fibre.

W. von Bezold calls attention to the experiments on thermal conductivity by Tyndall, which led him in 1871 to experiment upon the Lichtenberg figures formed upon wood. At that time von Bezold found that the Lichtenberg figures on plates of wood cut with the grain fibre were elliptical with the major axis at right angles to the fibre, while the ellipses obtained upon the same wood by Senarmont's methed of testing thermal conductivity were much more elongated and in the direction of the fibre. The author was able to give to a hard rubber plate an anisotropic character by pasting parallel strips of tinfoil upon the back, whereupon it gave Lichtenberg figures similar to those on a piece of wood cut with the grain. He suggests experiments with a dielectric in which are imbedded rods of a conductor or a dielectric of different inductive capacity.

A. Righi points out that he had presented a paper before the Academy of Sciences at Bologna, which Mr. Mack evidently had not seen, although it was read nearly six months before his article appeared. On that occasion Mr. Righi described experiments similar to those of Mack, wherein he obtained identical results, even identifying elliptical and circular polarization in wood.

In conclusion, I may state that I have recently examined thin films of wood between crossed Nicols, using sunlight, and found in all cases the behavior toward light the same as that described for electric waves, albeit, one sees that the double refraction is not shared equally by all the components of the wood.

William Hallock.

Distribution of the Magnetic Declination in Alaska and Adjacent Waters for the Year, 1895. Bull. No. 34, U. S. Coast and Geodetic Survey. $8^{\circ}, 6 \mathrm{pp}$. and 1 chart.

The above is a brief abstract of a fuller report to be published later by C. A. Schott, Assistant. As the title indicates, the paper attempts to give the latest representation of the distribution of the magnetic declination for the region indicated. It hence replaces the earlier (1890) attempt and gives evidence of a decided improvement. On account of the wide extent of the region involved and the paucity and irregular distribution of the observations, the analytical method of representing the available declinations was adopted. The formula established gives a very satisfactory accord with the observations covering a territory from $47^{\circ} .4$ to $71^{\circ} .3 \mathrm{~N}$ and from $122^{\circ} .4$ to $156^{\circ} .5 \mathrm{~W}$ of Gr. The largest discrepancy between the observed and computed 'declination is but $0^{\circ} .9$; the probable error of a single representation, $\pm 19^{\prime}$.

On the chart the isogonics or lines of equal magnetic declination, as obtained with the aid of the formula, are given at intervals of one degree for the region covered by the above title.

L. A. Bauer. 